http://jmscr.igmpublication.org/home/

ISSN (e)-2347-176x ISSN (p) 2455-0450

crossref DOI: https://dx.doi.org/10.18535/jmscr/v9i11.02

Journal Of Medical Science And Clinical Research

IGM Publication

An Official Publication of IGM Publication

\title{
Periumbilical Perforating Pseudoxanthoma Elasticum / PPPXE - A Rare Case Report
}

\author{
Authors \\ Dr Prajul Mehta ${ }^{1}$, Dr Ashwani Rana ${ }^{2 *}$ \\ ${ }^{1}$ MD Dermatology CH Theog, Shimla, H.P. India \\ ${ }^{2}$ MD Dermatology CH Joginder-nagar, Mandi, H.P. India \\ *Corresponding Author \\ Dr Ashwani Rana \\ MD Dermatology CH Joginder-nagar, Mandi, H.P. India
}

\begin{abstract}
Pseudoxanthoma elasticum (PXE) is a rare inherited disorder involving degeneration and pathological mineralization of the elastic fibers. It predominantly involves the skin, eyes and cardiovascular system. Periumbilical perforating pseudoxanthoma elasticum (PPPXE) is a rare localized variant of PXE frequently seen in obese, multiparous, middle-aged women. We hereby report a rare case of PPPXE in a multiparous woman, presented with a large yellowish plaque around the umbilicus without any systemic involvement. The other sites usually affected were not involved.
\end{abstract}

Keywords: PXE, PPPXE, elastic fibres.

\section{Introduction}

Pseudoxanthoma elasticum is a rare autosomal recessive disease that mainly involves the skin, eyes, and cardiovascular system. ${ }^{1}$ It is characterized by pathological mineralization of the elastic fibers in the connective tissue, affecting principally the dermis of skin, media, and intima of blood vessels and Bruch's membrane of the eye. The genetic defect of the disorder is located on chromosome 16p13.1 and disease is caused by the lack of functional ABCC6 protein, which in turn causes extracellular accumulation and deposition of calcium and other minerals in the elastic tissue. $^{2}$ Periumbilical perforating pseudoxanthoma elasticum (PPPXE) is a rare localized acquired varint of PXE, frequently in obese, multiparous, middle-aged women. It is characterized clinically by yellowish, lax, wellcircumscribed, reticulated or cobblestoned patches or plaques in the periumbilical region. Multiparity, obesity, massive ascites, and abdominal surgery are thought to the initiating factors.

\section{Case Report}

A 62 year old female presented with a slightly pruritic cutaneous lesion over the abdomen since 2 years. On examination there was presence of multiple yellowish papules, coalesced to form a larger plaque around the umbilicus. Also there was presence of few keratotic papules over the existing plaque. (Figure-1) Her medical history was not significant, she denied history of similar lesions in the family. The routine laboratory tests 
were within normal limits. The angioid streaks were not seen on ophthalmologic examination. As the patient refused for biopsy, based on clinical finding diagnosis of PXE was made. Due to her complaint of pain abdomen, an endoscopy was advised and a trial of therapy with topical steroids and topical retinoic acids was prescribed. The patient was lost to follow up.

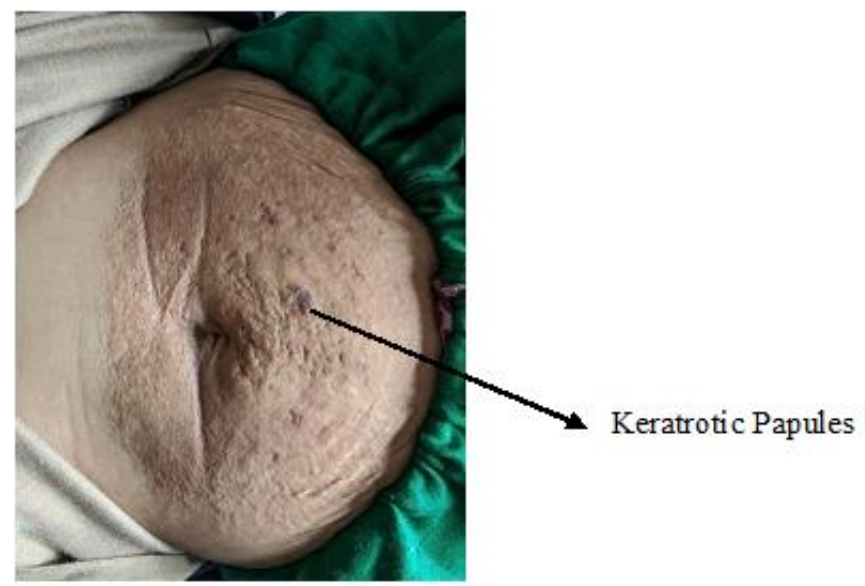

Figure 1 shows a reticulated yellowish plaque over the abdomen with discrete keratotic papules

\section{Discussion}

The term PPPXE was first proposed by Hicks et al., in 1979. ${ }^{3}$ Periumbilical perforating pseudoxanthoma elasticum (PPPXE) is a rare variant of PXE, usually presents with welldemarcated, hyperpigmented, periumbilical plaques with keratotic papules at the periphery. The classification of PPPXE is still controversial. In some cases, it occurs as a localized lesion without systemic involvement of hereditary PXE; typical patient is a multiparous, obese, middle aged, black woman with multiple abdominal surgery or trauma. That is why some authors suggest that it is an acquired localized form seperated from hereditary PXE. ${ }^{5}$ The histopathology reveals morphologically altered and calcified elastic fibers throughout the dermis that are extruded to the skin by transepidermal elimination. ${ }^{4}$ There were no features of hereditary pseudoxanthoma elasticum in the present case report.

This condition has no specific treatment. Topical steroids and retinoids have shown no benefit. ${ }^{5}$

\section{Declaration of Patient Consent}

The authors certify that they have obtained all appropriate patient consent forms. In the form the patient(s) has/have given his/her/ their consent for his/her/their images and other clinical information to be reported in the journal. The patients understand that their names and initials will not be published and due efforts will be made to conceal their identity, but anonymity cannot be guaranteed.

\section{Conflict of Interest- Nil}

\section{References}

1. Chassaing N, Martin L, Calvas P, Le Bert M, Hovnanian A. Pseudoxanthoma elasticum: a clinical, pathophysiological and genetic update including 11 novel ABCC6 mutations. J Med Genet. 2005; 42:881-892.

2. Esquivel-Pinto IA, Vega-Memije ME, Alvarado-Delgadillo A, CampuzanoGarcia AE, Manríquez-Robles A. Pseudoxanthoma Elasticum: Report of Two Cases. Case Rep Dermatol. 2021;13(1):230-7.

3. Hicks J, Carpenter CL Jr, Reed RJ. Periumbilical perforating pseudoxanthoma elasticum. Arch Dermatol 1979;115:300-3.

4. Jha AK, Zeeshan MD, Sinha BK, Singh A, Agrawal P. Periumbilical perforating pseudoxanthoma elasticum: a rare case report. Dermatol Pract Concept. 2018; 8(2):75-7.

5. Kocaturk E, Kavala M, Zindanci I, Koc M. Periumbilical perforating pseudoxanthoma elasticum. Indian J Dermatol Venereol Leprol 2009;75:329-3. 